\title{
Combined effects of reproductive and hormone factors and obesity on the prevalence of knee osteoarthritis and knee pain among middle-aged or older Chinese women: a cross-sectional study
}

\author{
Min Zhou ${ }^{1,2}$, Jianghao Chen ${ }^{1,2}$, Dongming Wang ${ }^{1,2}$, Chunmei Zhu ${ }^{1,2}$, Youjie Wang ${ }^{1,3}$ and Weihong Chen ${ }^{1,2^{*}}$
}

\begin{abstract}
Background: Knee osteoarthritis (KOA) is one form of degenerative arthritis that results from the breakdown of cartilage and underlying bone. The prevalence of KOA is considerably higher in women than in men; however, the reason for this difference has not been thoroughly elucidated to date. The aim of the present study was to estimate the effects of reproductive and hormone factors and obesity on KOA prevalence among Chinese women.

Methods: The cross-sectional study included 7510 women with a mean age of $62.6 \pm 8.6$ years. Knee pain was defined as pain or aching stiffness on most days for at least 1 month during the past 12 months or persistent pain or aching stiffness within the past week. Clinical KOA was diagnosed based on both pain complaints and a Kellgren-Lawrence grade $\geq 2 X$-ray radiograph of at least one knee.

Results: Oral contraceptives use (OR 1.18, 1.05-1.34), $\geq 3$ pregnancies (1.38, 1.20-1.60), and postmenopausal hormone replacement therapy $(\mathrm{HT})(1.59,1.23-2.06)$ were positively associated with knee pain, while oral contraceptives use $(1.28,1.04-1.57)$, and HT $(1.79,1.21-2.65)$ were positively associated with clinical KOA. Obesity and oral contraceptives use showed additive and multiplicative effects on knee pain. The OR for knee pain among women with a BMI $\geq 24 \mathrm{~kg} / \mathrm{m}^{2}$ and oral contraceptives use was $2.00(1.68-2.38)$ compared with women with a BMl $<24 \mathrm{~kg} / \mathrm{m}^{2}$ and no oral contraceptives use.
\end{abstract}

Conclusions: A high number of pregnancies, oral contraceptives use, and HT are independent risk factors for KOA, and the effects of reproductive and hormone factors on KOA may be increased by obesity.

Keywords: Female, Knee pain, Knee osteoarthritis, Reproductive and hormone factors, Obesity

\footnotetext{
* Correspondence: wchen@mails.tjmu.edu.cn

${ }^{1}$ Key Laboratory of Environment and Health in Ministry of Education \& Ministry of Environmental Protection, and State Key Laboratory of Environmental Health (Incubating), School of Public Health, Tongji Medical College, Huazhong University of Science and Technology, Hangkong Road 13, Wuhan 430030, Hubei, China

${ }^{2}$ Department of Occupational and Environmental Health, School of Public Health, Tongji Medical College, Huazhong University of Science and Technology, Hangkong Road 13, Wuhan 430030, Hubei, China

Full list of author information is available at the end of the article
}

(c) The Author(s). 2018 Open Access This article is distributed under the terms of the Creative Commons Attribution 4.0 International License (http://creativecommons.org/licenses/by/4.0/), which permits unrestricted use, distribution, and reproduction in any medium, provided you give appropriate credit to the original author(s) and the source, provide a link to the Creative Commons license, and indicate if changes were made. The Creative Commons Public Domain Dedication waiver (http://creativecommons.org/publicdomain/zero/1.0/) applies to the data made available in this article, unless otherwise stated. 


\section{Background}

Knee osteoarthritis (KOA) is one form of degenerative arthritis that results from the breakdown of cartilage and underlying bone. A high prevalence of clinical KOA, ranging from 5.6 to $28.9 \%$, has been reported across regions and countries [1-3]. Knee pain is the most common presenting feature of KOA. Disability associated with knee pain affects up to $10 \%$ of adults aged 55 or older [4]. Lower limb disability following $\mathrm{KOA}$ is thought to be an important cause of poor quality of life and work limitations. KOA is reported to be one of the largest economic burdens worldwide $[5,6]$.

Accumulating evidence suggests that the prevalence of KOA is much higher in women than in men. The results from the Johnston County (North Carolina, USA) Osteoarthritis Project reported that the prevalence of symptomatic KOA among women and men was $17.6 \%$ and $14.5 \%$, respectively [3]. The China Health and Retirement Longitudinal Study showed that the prevalence of symptomatic KOA was higher in women $(10.3 \%)$ than that in men $(5.7 \%)$ [7]. The reason for the higher prevalence of KOA in women remains unclear. In addition to physical characteristics, female-specific physiological phenomenon may play an important role in the development and progression of KOA. Currently, several papers have indicated that reproductive and hormone factors may contribute to the elevated prevalence of KOA among females. Szoeke and colleagues found that hormone replacement therapy was a risk factor for KOA in a study of 224 Australian women [8]. A multicenter osteoarthritis study with 1618 women reported that an increased number of pregnancies was positively associated with an elevated incidence of KOA [9]. Alternations in sex hormones might affect bone turnover via the estrogen receptors in the musculoskeletal system and disturb the bone and cartilage metabolic balance [10, 11]. Reproductive and hormone factors are also associated with obesity [12, 13], with the latter being reported to increase knee joint burden [14]. However, whether obesity modifies the association between reproductive and hormone factors and KOA has not been adequately examined to date.

The objective of this study was to evaluate the independent and combined effects of reproductive and hormone factors and obesity on the prevalence of knee pain and clinical KOA among middle-aged and older Chinese females.

\section{Methods}

\section{Design}

The study design was cross-sectional.

\section{Participants}

The participants in the present study came from Dongfeng-Tongji cohort that was reported previously [15]. Questionnaires were administered face-to-face by trained interviewers to collect information on demographics, medical history, lifestyle, occupational history, and reproductive and hormone factors. After the interviews, all participants underwent physical examinations. A total of 14,438 participants, i.e., those that underwent physical examinations at the Central Hospital of the Dongfeng Motor Corporation, had their knees examined (for tenderness, range of motion, extension test, and McMurray's test) and were questioned about knee symptoms (pain or aching stiffness in or around the knee). After excluding individuals with missing data regarding knee health status $(n=182)$ or women with missing information regarding reproductive and hormone factors $(n=50)$, the response rate was $98.4 \%$. Participants with knee surgery caused by accidental injury, which was associated with secondary KOA $(n=247)$, or with a history of rheumatoid arthritis $(n=103)$, or male gender $(n=6346)$ were further excluded, and 7510 women were included in the final analysis.

\section{Assessment of knee pain and clinical KOA}

Knee pain was diagnosed when any knee met the following criteria: 1) pain or aching stiffness in or around the knee on most days for at least 1 month during the past 12 months and/or 2) persistent pain or aching stiffness in or around the knee within the past week.

Information regarding self-reported clinically diagnosed KOA was collected from the questionnaires and confirmed by insurance records and treatment information. Clinical KOA was diagnosed only if the patient had knee pain complaints and bilateral weight-bearing anteroposterior X-ray radiographs showing a Kellgren and Lawrence grade $\geq 2$ for at least one knee [16].

\section{Assessment of reproductive and hormone factors}

Information regarding reproductive and hormone factors was collected from the questionnaires. Pregnancy times were defined as the total number of pregnancies and were categorized into three subgroups: $\leq 1,2$, and $\geq 3$, and the limited number of nulliparous women were categorized as $\mathrm{a} \leq 1$ group $(n=60)$. Abortion was defined as terminating pregnancy before the 28th gestational week or before the fetus weighed $1000 \mathrm{~g}$. Menopause was defined as no vaginal bleeding for at least one year. The duration of post-menopausal status was categorized as 0 (pre-menopause), $<9,9-17$, and $\geq 17$ years. Information on past oral contraceptives use and hormone replacement therapy (HT) history was collected by asking "Have you ever taken any oral contraceptive drugs?" and "Have you ever used any hormone replacement therapy?"

\section{Assessment of obesity}

Body height and weight were measured to the nearest $0.1 \mathrm{~cm}$ and $0.1 \mathrm{~kg}$ with participants wearing light indoor clothing. Body mass index (BMI) was calculated from 
weight in kilograms divided by the body height in square meters and was categorized into normal bodyweight or below $\left(<24.0 \mathrm{~kg} / \mathrm{m}^{2}\right)$, overweight $\left(24.0-28.0 \mathrm{~kg} / \mathrm{m}^{2}\right)$, or obese $\left(\geq 28.0 \mathrm{~kg} / \mathrm{m}^{2}\right)$ according to World Health Organization recommended BMI cut-off points for Asian populations [17].

\section{Assessment of covariates}

Information on age, gender (male/ female), education level (elementary or lower/ junior high school/ high school/ college or higher), drinking status (current/ former/ never), physical exercise (yes/ no), and occupational history (job titles, calendar years of each job, job content) was collected from questionnaires.

Participants who had been drinking alcohol as often as once per week for at least 6 months were considered to be current drinkers. Physical activity was defined as regular leisure time exercise of at least 20 min per day over the past 6 months.

Shift work was identified as working with a schedule involving unusual working hours as opposed to the normal daytime work schedule, i.e., from 8:00 to 17:00 in China, for at least one year. There were 2 common types of shift work in Dongfeng Motor Corporation: (1) two-shifts, day work (8:00-20:00) and night work (20:00-next 8:00) shifted in weekly rotation; (2) three-shifts, during which 3 crews of workers succeed each other at 8:00, 16:00, and 00:00. The workers in any kind of shift work were required to take turns working in the early morning and at night.

Based on the job held for the longest duration, work posture was grouped into sitting, standing, squatting or kneeling, or bending if the participant accumulatively held the posture for half the time or longer during each shift (i.e., $\geq 4 \mathrm{~h}$ for most cases) according to the description of the job content.

\section{Statistical analysis}

Basic characteristics of participants were presented as the means (standard deviation, SD) compared using Student' $\mathrm{s}$ t-test for continuous variables and as numbers (percentages) compared using the Chi-square test for categorical

Table 1 Basic characteristics of the participants $(n=7510)$

\begin{tabular}{|c|c|c|c|c|c|c|}
\hline \multirow[t]{2}{*}{ Variables } & \multicolumn{3}{|l|}{ Knee pain } & \multicolumn{3}{|l|}{ Clinical KOA } \\
\hline & Yes $(n=3496)$ & No $(n=4014)$ & $p$-value & Yes $(n=640)$ & No $(n=6870)$ & $p$-value \\
\hline Age (years, mean $\pm S D$ ) & $63.1 \pm 8.5$ & $61.1 \pm 8.6$ & $<0.01^{*}$ & $65.1 \pm 8.6$ & $61.9 \pm 8.5$ & $<0.01^{*}$ \\
\hline $\mathrm{BMI}\left(\mathrm{kg} / \mathrm{m}^{2}\right.$, mean $\left.\pm \mathrm{SD}\right)$ & $24.7 \pm 3.6$ & $23.8 \pm 3.3$ & $<0.01^{*}$ & $25.3 \pm 3.8$ & $24.1 \pm 3.4$ & $<0.01^{*}$ \\
\hline Times of pregnancy (mean \pm SE) & $3.21 \pm 0.02$ & $3.00 \pm 0.02$ & $<0.01^{*}$ & $3.33 \pm 0.06$ & $3.08 \pm 0.01$ & $<0.01^{*}$ \\
\hline Abortion (\%) & $2329(67.8)$ & $2652(67.8)$ & 0.95 & $413(65.8)$ & $4568(68.0)$ & 0.25 \\
\hline Oral contraceptives use (\%) & 656(18.9) & $672(16.9)$ & $0.02^{*}$ & 129(20.4) & 1199(17.6) & 0.08 \\
\hline Years of post-menopause (mean \pm SD) & $13.8 \pm 9.3$ & $11.9 \pm 9.2$ & $<0.01^{*}$ & $15.8 \pm 9.5$ & $12.5 \pm 9.2$ & $<0.01^{*}$ \\
\hline History of HT (\%) & 126(3.9) & $99(2.8)$ & $0.01^{*}$ & $26(4.3)$ & 199(3.2) & $0.02^{*}$ \\
\hline Education (\%) & & & $<0.01^{*}$ & & & 0.36 \\
\hline Elementary or lower & $807(23.2)$ & 797(20.0) & & 154(24.1) & $1450(21.2)$ & \\
\hline Junior high school & $1278(36.7)$ & 1424(35.7) & & 229(35.8) & $2473(36.2)$ & \\
\hline High school & 1071(30.8) & 1379(34.5) & & 199(31.1) & $2251(32.9)$ & \\
\hline College or higher & $325(9.3)$ & 393(9.8) & & $57(8.9)$ & $661(9.7)$ & \\
\hline Alcohol consumption (\%) & & & 0.42 & & & 0.77 \\
\hline Never & $3031(86.9)$ & $3513(87.7)$ & & $557(87.2)$ & $5987(87.4)$ & \\
\hline Current & $410(11.8)$ & 433(10.8) & & $71(11.1)$ & $772(11.2)$ & \\
\hline Former & $47(1.3)$ & $58(1.5)$ & & $11(1.7)$ & $94(1.4)$ & \\
\hline Physical exercise (\%) & 3096(88.6) & 3605(89.8) & 0.07 & $577(90.1)$ & $6124(89.2)$ & 0.43 \\
\hline Work posture (\%) & & & 0.22 & & & 0.29 \\
\hline Sitting & 1031(29.6) & 1268(31.7) & & $207(32.5)$ & 2092(30.6) & \\
\hline Standing & $1765(50.7)$ & 1942(48.6) & & $320(50.2)$ & $3387(49.5)$ & \\
\hline Bending & $535(15.4)$ & 616(15.4) & & $90(14.1)$ & $1061(15.5)$ & \\
\hline Squatting or kneeling & $150(4.3)$ & 173(4.3) & & $20(3.1)$ & $303(4.4)$ & \\
\hline Shift work & $1495(42.8)$ & $1522(37.9)$ & $<0.01^{*}$ & $264(41.2)$ & $2753(40.1)$ & 0.56 \\
\hline
\end{tabular}

$B M I$ body mass index, $H T$ post-menopausal hormone replacement therapy, $S D$ standard deviation, $S E$ standard error, Continuous variables were described as the mean \pm SD and compared by Student's t-test, and categorical variables were described as number (percentage) and compared by Chi-square test. ${ }^{*} p$-value $<0.05$ 
Table 2 ORs and 95\% Cl of risk factors for knee pain and clinical KOA (logistic regression)

\begin{tabular}{|c|c|c|c|c|c|c|c|c|}
\hline \multirow[t]{2}{*}{ Variables } & \multicolumn{4}{|c|}{ Knee pain } & \multicolumn{4}{|c|}{ Clinical KOA } \\
\hline & case & control & Model 1 & Model 2 & case & control & Model 1 & Model 2 \\
\hline Age (years) & NA & NA & $1.03(1.02-1.03)^{*}$ & & NA & NA & $1.04(1.03-1.05)^{*}$ & \\
\hline $\mathrm{BMI}\left(\mathrm{kg} / \mathrm{m}^{2}\right)$ & NA & NA & $1.08(1.07-1.10)^{*}$ & & NA & NA & $1.10(1.08-1.12)^{*}$ & \\
\hline \multicolumn{9}{|l|}{ Education } \\
\hline Elementary or lower & 807 & 797 & 1 & & 154 & 1450 & 1 & \\
\hline Junior high school & 1278 & 1424 & $1.06(0.93-1.21)$ & & 229 & 2473 & $1.20(0.96-1.51)$ & \\
\hline High school & 1071 & 1379 & $1.03(0.89-1.18)$ & & 199 & 2251 & $1.39(1.09-1.77)^{*}$ & \\
\hline College or higher & 325 & 393 & $1.05(0.87-1.26)$ & & 57 & 661 & $1.21(0.87-1.67)$ & \\
\hline \multicolumn{9}{|l|}{ Alcohol consumption } \\
\hline Never & 3031 & 3513 & 1 & & 557 & 2987 & 1 & \\
\hline Current & 410 & 433 & $1.21(1.04-1.40)^{*}$ & & 71 & 772 & $1.18(0.91-1.54)$ & \\
\hline Former & 47 & 58 & $0.99(0.67-1.48)$ & & 11 & 94 & $1.42(0.75-2.70)$ & \\
\hline \multicolumn{9}{|l|}{ Physical exercise } \\
\hline No & 400 & 408 & 1 & & 63 & 745 & 1 & \\
\hline Yes & 3096 & 3605 & $0.89(0.77-1.03)$ & & 577 & 6124 & $1.12(0.85-1.47)$ & \\
\hline \multicolumn{9}{|l|}{ Work posture } \\
\hline Sitting & 1031 & 1268 & 1 & & 207 & 2092 & 1 & \\
\hline Standing & 1765 & 1942 & $1.12(1.01-1.24)^{*}$ & & 320 & 3387 & $0.96(0.80-1.15)$ & \\
\hline Bending & 535 & 616 & $1.07(0.93-1.23)$ & & 90 & 1061 & $0.86(0.66-1.11)$ & \\
\hline Squatting kneeling & 150 & 173 & $1.07(0.84-1.35)$ & & 20 & 303 & $0.67(0.42-1.07)$ & \\
\hline \multicolumn{9}{|l|}{ Shift work } \\
\hline No & 2001 & 2492 & 1 & & 376 & 4117 & 1 & \\
\hline Yes & 1495 & 1522 & $1.28(1.17-1.41)^{*}$ & & 264 & 2753 & 1.13(0.96-1.34) & \\
\hline \multicolumn{9}{|l|}{ Times of pregnancy } \\
\hline$\leq 1$ & 387 & 553 & 1 & 1 & 67 & 873 & 1 & 1 \\
\hline 2 & 774 & 1050 & $1.05(0.90-1.24)$ & $0.97(0.82-1.15)$ & 134 & 1690 & $0.90(0.66-1.23)$ & 0.97(0.70-1.34) \\
\hline$\geq 3$ & 2335 & 2411 & $1.38(1.20-1.60)^{*}$ & $1.15(0.98-1.34)$ & 439 & 4307 & $0.91(0.69-1.21)$ & $0.98(0.73-1.32)$ \\
\hline \multicolumn{9}{|l|}{ Abortion } \\
\hline No & 1104 & 1261 & 1 & 1 & 215 & 2150 & 1 & 1 \\
\hline Yes & 2329 & 2652 & $1.01(0.91-1.11)$ & $1.08(0.98-1.20)$ & 413 & 4568 & 1.06(0.88-1.26) & $1.01(0.85-1.22)$ \\
\hline \multicolumn{9}{|l|}{ History of HT } \\
\hline No & 3088 & 3418 & 1 & 1 & 580 & 5926 & 1 & 1 \\
\hline Yes & 126 & 99 & $1.59(1.23-2.06)^{*}$ & $1.56(1.20-2.04)^{*}$ & 26 & 199 & $1.79(1.21-2.65)^{*}$ & $1.65(1.11-2.47)^{*}$ \\
\hline \multicolumn{9}{|l|}{ Years of post-menopause } \\
\hline No & 239 & 444 & 1 & 1 & 29 & 654 & 1 & 1 \\
\hline$<9$ & 887 & 1208 & $1.30(1.08-1.56)^{*}$ & $1.31(1.08-1.58)^{*}$ & 134 & 1961 & $1.33(0.88-2.01)$ & 1.36(0.89-2.09) \\
\hline $7-19$ & 1065 & 1161 & $1.42(1.16-1.76)^{*}$ & $1.48(1.19-1.83)^{*}$ & 187 & 2039 & 1.35(0.87-2.09) & 1.38(0.89-2.16) \\
\hline$\geq 17$ & 1262 & 1148 & $1.46(1.12-1.91)^{*}$ & $1.54(1.17-2.01)^{*}$ & 285 & 2125 & $1.38(0.82-2.32)$ & $1.39(0.82-2.35)$ \\
\hline \multicolumn{9}{|l|}{ Contraceptives use } \\
\hline No & 2813 & 3307 & 1 & 1 & 504 & 5616 & 1 & 1 \\
\hline Yes & 656 & 672 & $1.18(1.05-1.34)^{*}$ & $1.17(1.04-1.33)^{*}$ & 129 & 1199 & $1.28(1.04-1.57)^{*}$ & $1.25(1.01-1.54)^{*}$ \\
\hline
\end{tabular}

$B M I$ body mass index, $H T$ post-menopausal hormone replacement therapy, $N A$ not applicable, ${ }^{*} p$-value $<0.05$

Model 1: adjusted for age (continuous) and BMI (continuous)

Model 2: adjusted for age (continuous), BMI (continuous), education, alcohol drinking, physical exercise, work posture, and shift work 
variables. Logistic regression models were used to calculate adjusted odds ratios (ORs) and 95\% confidence intervals (CIs) for related factors associated with knee pain or clinical KOA. Model 1 adjusted for age and BMI, because previous research suggested that they were important risk factors for KOA [18]. Model 2 further adjusted for education, physical exercise, alcohol drinking, work posture, and shift work, in the event they might affect knee health status or hormone levels $[19,20]$. To explore the influence of multiple independent factors on knee pain or clinical $\mathrm{KOA}$, we used multivariable logistic regression with a stepwise selection procedure, starting with variables of interest (including times of pregnancy, abortion, post-menopause duration, HT, contraceptives use, age, BMI, education, physical exercise, alcohol drinking, work posture, and shift work) and ending with variables that were statistically significantly associated with a $p$-value $<0.05$. The multiplicative effects of obesity and reproductive and hormone factors on knee pain and clinical KOA were calculated using multivariable logistic regression analyses in which the multiplicative interaction terms were added. To evaluate the additive interaction, the attributable proportion of interaction (AP) were calculated in an additive interaction model [21]. All statistical analyses were performed using SAS 9.4 software (SAS Institute, Cary, NC, USA).

\section{Results}

The basic characteristics of the participants were shown in Table 1. The mean age of participants was $62.6 \pm$ 8.6 years old. The prevalence of knee pain and clinical KOA was $46.6 \%(n=3496)$ and $8.5 \%(n=640)$, respectively. Participants with knee pain or clinical KOA were of older age, higher BMI, had more pregnancies, a longer post-menopause duration, and more use of HT than their unaffected colleagues. No differences in alcohol drinking or workload were observed between participants with or without knee pain or clinical KOA.

As shown in Table 2, advanced age and elevated BMI were associated with an elevated prevalence of knee pain and clinical KOA. After adjusting for age and BMI, the ORs for knee pain and clinical KOA among women with $\geq 3$ pregnancies were $1.38(1.20-1.60)$ and 0.91 (0.69-1.21), respectively, when compared with those with $\leq 1$ pregnancy. There were 1328 participants (17.7\%) that reported taking oral contraceptives during their fertility period. Participants who had taken oral contraceptives had a higher prevalence of knee pain (OR 1.18, 95\% CI 1.05-1.34) and clinical KOA $(1.28,1.04-1.57)$ than those who had never used oral contraceptives. Compared with women of pre-menopausal status, a significantly increased prevalence of knee pain was observed among post-menopausal women. The ORs for knee pain among women with $<9$, $9-17$, and $\geq 17$ years of post-menopausal status were 1.30
(1.08-1.56), 1.42 (1.16-1.76), and 1.46 (1.12-1.91), respectively. The corresponding prevalence for clinical KOA was increased, although not statistically significantly, with ORs of 1.33 (0.88-2.01), 1.35 (0.87-2.09), and 1.38 (0.82-2.32), respectively. HT was significantly associated with the increased prevalence of knee pain $(1.59,1.23-2.06)$ and clinical KOA (1.79, 1.21-2.65) among post-menopausal women. Further adjustments for education, physical exercise, alcohol drinking, work posture, and shift work did not change these associations.

As shown in Table 3, the results of stepwise multivariable logistic regression analysis indicated that $<9$ years (1.32, $1.09-1.59), 9-17$ years $(1.46,1.18-1.80)$, and $\geq$ 17 years $(1.47,1.12-1.93)$ post-menopause, oral contraceptives use $(1.14 ; 1.01-1.29)$, HT $(1.52 ; 1.16-1.98)$, shift work (1.28; 1.16-1.41), advanced age (1.01; 1.00-1.02), and elevated BMI $(1.08 ; 1.06-1.09)$ were independently positively associated with an increased prevalence of knee pain. In addition, use of oral contraceptives $(1.26$; 1.02 $1.55)$, HT (1.66; 1.12-2.48), aging (1.04; $1.03-1.05)$, and obesity $(1.09 ; 1.07-1.12)$ were independently positively associated with an increased prevalence of clinical KOA.

Table 4 showed the joint effects of obesity (BMI $\geq 24.0 \mathrm{~kg} / \mathrm{m}^{2}$ ) and reproductive and hormone factors on knee pain and KOA. The results showed multiplicative interactions $(p=0.019)$ and additive (AP 0.26; 95\% CI $0.11-$ 0.42 ) effects of obesity and oral contraceptives use on knee pain. Compared with women with a BMI $<24.0 \mathrm{~kg} / \mathrm{m}^{2}$ and no contraceptives use, the ORs of knee pain among

Table 3 ORs of risk factors for knee pain and clinical KOA (multivariable stepwise logistic regression)

\begin{tabular}{lll}
\hline Variables & Knee pain & Clinical KOA \\
\hline $\begin{array}{lll}\text { Times of pregnancy } \\
\leq 1\end{array}$ & 1 & NA \\
2 & $0.95(0.80-1.13)$ & NA \\
$\geq 3$ & $1.12(0.96-1.31)$ & NA \\
Duration of post-menopause (years) & \\
No & 1 & NA \\
$<9$ & $1.32(1.09-1.59)^{*}$ & NA \\
$9-17$ & $1.46(1.18-1.80)^{*}$ & NA \\
$\geq 17$ & $1.47(1.12-1.93)^{*}$ & NA \\
History of HT & $1.52(1.16-1.98)^{*}$ & $1.66(1.12-2.48)^{*}$ \\
Contraceptives use & $1.14(1.01-1.29)^{*}$ & $1.26(1.02-1.55)^{*}$ \\
Age (years) & $1.01(1.00-1.02)^{*}$ & $1.04(1.03-1.05)^{*}$ \\
BMl (kg/m $\left.{ }^{2}\right)$ & $1.08(1.06-1.09)^{*}$ & $1.09(1.07-1.12)^{*}$ \\
Shift work & $1.28(1.16-1.41)^{*}$ & NA \\
\hline
\end{tabular}

$B M I$ body mass index, $H T$ post-menopausal hormone replacement therapy, $N A$ not applicable, and the variable was insignificantly associated with clinical $\mathrm{KOA}$ in the multivariable stepwise logistic regression analysis. The model initially included times of pregnancy, abortion, post-menopause duration, HT, contraceptives use, age, BMI, education, physical exercise, drinking, work posture, and shift work. ${ }^{*} p$-value $<0.05$ 
Table 4 Interaction effects of obesity and reproductive and hormone factors on knee pain and clinical KOA

\begin{tabular}{|c|c|c|c|c|c|c|}
\hline \multirow[t]{2}{*}{ Variables } & \multicolumn{3}{|l|}{ Knee pain } & \multicolumn{3}{|l|}{ Clinical KOA } \\
\hline & $\mathrm{OR}(95 \% \mathrm{Cl})$ & $\begin{array}{l}\text { Multiplicative } \\
\text { interaction, } p \text {-value }\end{array}$ & $\begin{array}{l}\text { Additive } \\
\text { interaction, AP }\end{array}$ & $\mathrm{OR}(95 \% \mathrm{Cl})$ & $\begin{array}{l}\text { Multiplicative } \\
\text { interaction, } p \text {-value }\end{array}$ & Additive interaction, AP \\
\hline $\mathrm{BMI}+$ pregnancy & & 0.570 & $0.08(0.07,0.22)^{*}$ & & 0.946 & $-0.02(-0.31,0.27)$ \\
\hline BMI $(-)$ pregnancy $(<3)$ & 1 & & & 1 & & \\
\hline BMI (-) pregnancy $(\geq 3)$ & $1.16(1.01-1.33)^{*}$ & & & $1.00(0.76-1.33)$ & & \\
\hline $\mathrm{BMI}(+)$ pregnancy $(<3)$ & $1.48(1.27-1.73)^{*}$ & & & $1.65(1.24-2.21)^{*}$ & & \\
\hline $\mathrm{BMI}(+)$ pregnancy $(\geq 3)$ & $1.78(1.55-2.04)^{*}$ & & & $1.63(1.26-2.12)^{*}$ & & \\
\hline BMI + abortion & & 0.544 & $0.07(-0.08,0.23)$ & & 0.288 & $-0.14(-0.42,0.15)$ \\
\hline BMI (-) abortion (-) & 1 & & & 1 & & \\
\hline BMI (-) abortion (+) & $1.06(0.92-1.23)$ & & & $1.20(0.90-1.60)$ & & \\
\hline BMI (+) abortion (-) & $1.48(1.25-1.74)^{*}$ & & & $1.90(1.42-2.55)^{*}$ & & \\
\hline BMI (+) abortion (+) & $1.66(1.44-1.92)^{*}$ & & & $1.85(1.40-2.42)^{*}$ & & \\
\hline $\mathrm{BMI}+$ menopause & & 0.329 & $0.18(-0.05,0.41)$ & & 0.298 & $-0.15(-0.67,0.38)$ \\
\hline BMI (-) menopause $(-)$ & 1 & & & 1 & & \\
\hline BMI $(-)$ menopause $(+)$ & $1.20(0.93-1.54)$ & & & $2.08(0.96-4.51)$ & & \\
\hline BMI $(+)$ menopause $(-)$ & $1.32(0.94-1.85)$ & & & $2.73(1.09-6.88)^{*}$ & & \\
\hline BMI $(+)$ menopause $(+)$ & $1.84(1.43-2.38)^{*}$ & & & $3.32(1.53-7.20)^{*}$ & & \\
\hline $\mathrm{BMI}+\mathrm{HT}$ & & 0.828 & $0.09(-0.33,0.51)$ & & 0.916 & $0.20(-0.33,0.74)$ \\
\hline BMI (-) HT (-) & 1 & & & 1 & & \\
\hline $\mathrm{BMI}(-) \mathrm{HT}(+)$ & $1.62(1.14-2.32)^{*}$ & & & $1.72(0.93-3.17)$ & & \\
\hline $\mathrm{BMI}(+) \mathrm{HT}(-)$ & $1.52(1.39-1.67)^{*}$ & & & $1.62(1.37-1.93)^{*}$ & & \\
\hline $\mathrm{BMI}(+) \mathrm{HT}(+)$ & $2.36(1.62-3.44)^{*}$ & & & $2.95(1.77-4.92)^{*}$ & & \\
\hline BMI + contraceptives use & & $0.019^{*}$ & $0.26(0.11-0.42)^{*}$ & & 0.133 & $-0.16(-0.54,0.22)$ \\
\hline BMI (-) contraceptives (-) & 1 & & & 1 & & \\
\hline BMI (-) contraceptives $(+)$ & $1.03(0.87-1.22)$ & & & $1.52(1.12-2.06)^{*}$ & & \\
\hline BMI (+) contraceptives (-) & $1.44(1.30-1.59)^{*}$ & & & $1.74(1.44-2.11)^{*}$ & & \\
\hline BMI (+) contraceptives $(+)$ & $2.00(1.68-2.38)^{*}$ & & & $1.96(1.46-2.62)^{*}$ & & \\
\hline
\end{tabular}

$A P$ attributable proportion of interaction, $H T$, post-menopausal hormone replacement therapy, BMI $(+) \geq 24.0 \mathrm{~kg} / \mathrm{m}^{2}, \mathrm{BMI}(-)<24.0 \mathrm{~kg} / \mathrm{m}^{2}$, Adjusted for age (continuous), education level, alcohol consumption, physical exercise, work posture, and shift work. ${ }^{*}$-value $<0.05$

women with a BMI $<24.0 \mathrm{~kg} / \mathrm{m}^{2}$ and contraceptives use, with a BMI $\geq 24.0 \mathrm{~kg} / \mathrm{m}^{2}$ and no contraceptives use, and with a BMI $\geq 24.0 \mathrm{~kg} / \mathrm{m}^{2}$ and contraceptives use were 1.03(0.87-1.22), 1.44(1.30-1.59), and 2.00(1.68-2.38), respectively. There was an additive effect of obesity and pregnancy on knee pain (AP 0.08; 95\% CI 0.07-0.22) but no statistically significant combined effects of obesity and reproductive and hormone factors on clinical KOA.

\section{Discussion}

In the present study, HT, use of oral contraceptives, aging and elevated BMI were associated with an elevated prevalence of knee pain and clinical KOA among female participants. A high number of pregnancies and post-menopausal status were independently associated with knee pain. Additionally, the results indicated multiplicative and additive effects of obesity and taking oral contraceptives and additive effects of obesity and pregnancy on knee pain among females.

Post-menopause status and estrogen deficiency have been reported to be associated with an increased risk of KOA [22], but the effects of post-menopausal HT on KOA were contradictory. A cross-sectional study reported a protective effect of $\mathrm{HT}$ on KOA among women with a mean age of 53 years [23]. Results from a randomized controlled trial and from the Framingham Study did not observe a significant association between $\mathrm{HT}$ and $\mathrm{KOA}[24,25]$. The case-control study from Sandmark and colleagues suggested that HT increased the risk of KOA [26]. In the present study, HT was independently associated with an elevated prevalence of knee pain and clinical KOA among post-menopause women, with ORs of $1.52(1.16-1.98)$ for knee pain and $1.66(1.12-2.48)$ 
for clinical KOA. Several factors might contribute to the varied results. First, the dose and duration regarding the use of hormone replacement varied among researches. Second, although estrogen receptors are found in the musculoskeletal system, the effect of post-menopausal hormone supplement on cartilage and bone was uncertain [27-30]. Third, ethnic differences might partially explain the varied results. Among females using HT, American Indians ran a higher risk of OA than Asians and Whites [31]. In addition, we have noticed that education level was higher among those using HT $(66.1 \%$ in high school or higher education) than those not taking HT (39.7\% in high school or higher education), which might suggest different lifestyles among women using or not using HT [32].

Our results suggested that a high number of pregnancies was associated with an elevated prevalence of KOA, which is consistent with previous study results $[9,33,34]$. Women that had more pregnancies tended to have a higher BMI due to postpartum weight retention [35, 36], and elevated BMI was associated with an imbalance of bone and cartilage metabolism [37, 38].

In the present study, oral contraceptives use and obesity showed combined effects on KOA. Oral contraceptives were reported to be associated with venous thromboembolism [39-41], and the latter lead to subchondral ischemia and ultimately bone dystrophy. In addition, both oral contraceptives use and obesity were reported to increase plasma total cholesterol and triglyceride levels [42-44], and hyperlipidemia might be a potential risk factor for bone and cartilage metabolism disorders $[45,46]$.

The strengths of our study include its large sample size, detailed information regarding demographics, reproductive and hormone factors, medical history, and occupational history for each participant, and examinations of knee joints. However, the present study had several limitations. First, we failed to collect data of weight retention for each pregnancy and therefore we could not distinguish the effects of weight retention from pregnancy on KOA from the effect of total body weight change. Second, we were unable to determinate the estrogen levels of each participant and the association between hormone-related factors and KOA is unknown. Third, we did not provide knee X-ray examinations for the participants although all participants could undergo knee X-ray examinations at any time, which the company would pay for, if they experienced knee discomfort. Fourth, we estimated workload based on the job held for the longest duration. Participants might have had different jobs during their years of employment, but the workload during the shorter job durations was not considered.

\section{Conclusions}

This study indicated that reproductive and hormone factors, such as a high number of pregnancies, oral contraceptives use, and HT, were associated with an elevated prevalence of knee pain and clinical KOA. In addition, obesity could increase the effects of reproductive and hormone factors on knee pain or clinical KOA among middle-aged and older Chinese women.

\section{Abbreviations \\ AP: Attributable proportion of interaction; BMI: Body mass index: \\ $\mathrm{Cl}$ : Confidence interval; HT: Hormone replacement therapy; KOA: Knee osteoarthritis; NA: not applicable; OR: Odds ratio; SD: Standard deviation; SE: Standard error}

\section{Acknowledgments}

The authors are indebted to American Journal Experts for providing English language editing service.

\section{Funding \\ This work was supported by the National Natural Science Foundation of China [81573121]; and the Fundamental Research Funds for the Central Universities, Huazhong University of Science and Technology [2016JCTD116]. The funders played no role in the design of the study; collection, analysis, and interpretation of data; or writing the manuscript.}

\section{Availability of data and materials}

The datasets generated and analyzed during the current study are not publicly available due to participant confidentiality but are available from the corresponding author upon reasonable request.

\section{Authors' contributions}

Conceived and designed the study: MZ and WC. Collected the data: MZ, JC, DW, CZ, YW, and WC. Analyzed and interpreted the data: MZ, JC, DW, and WC. Wrote the first draft of the manuscript: MZ. Supervised the study: WC and YW. All authors were involved in revising the article critically for important intellectual content, and all authors approved the final version to be submitted for publication.

\section{Ethics approval and consent to participate}

This study was approved by the Medical Ethics Committee of Dongfeng General Hospital, Dongfeng Motor Corporation, and the School of Public Health, Tongji Medical College, Huazhong University of Science and Technology (Wuhan, Hubei, China). All participants signed a written informed consent.

\section{Consent for publication}

Not applicable.

\section{Competing interests}

The authors declare that they have no competing interests.

\section{Publisher's Note}

Springer Nature remains neutral with regard to jurisdictional claims in published maps and institutional affiliations.

\footnotetext{
Author details

${ }^{1}$ Key Laboratory of Environment and Health in Ministry of Education \& Ministry of Environmental Protection, and State Key Laboratory of Environmental Health (Incubating), School of Public Health, Tongji Medical College, Huazhong University of Science and Technology, Hangkong Road 13, Wuhan 430030, Hubei, China. ${ }^{2}$ Department of Occupational and Environmental Health, School of Public Health, Tongji Medical College, Huazhong University of Science and Technology, Hangkong Road 13, Wuhan 430030, Hubei, China. ${ }^{3}$ Department of Maternal and Child Health, School of Public Health, Tongji Medical College, Huazhong University of Science and Technology, Hangkong Road 13, Wuhan 430030, Hubei, China.
} 
Received: 8 June 2018 Accepted: 12 October 2018

Published online: 22 October 2018

\section{References}

1. Chen JC, Linnan L, Callahan LF, Yelin EH, Renner JB. Workplace policies and prevalence of knee osteoarthritis: the Johnston County osteoarthritis project. Occup Environ Med. 2007;64:798-805.

2. Mannoni A, Briganti MP, Di Bari M, Ferrucci L, Costanzo S, Serni U, et al. Epidemiological profile of symptomatic osteoarthritis in older adults: a population based study in Dicomano, Italy. Ann Rheum Dis. 2003;62:576-8.

3. Callahan LF, Shreffler J, Siaton BC, Helmick CG, Schoster B, Schwartz TA, et al. Limited educational attainment and radiographic and symptomatic knee osteoarthritis: a cross-sectional analysis using data from the Johnston County (North Carolina) osteoarthritis project. Arthritis Res Ther. 2010;12:R46.

4. Peat G, McCarney R, Croft P. Knee pain and osteoarthritis in older adults: a review of community burden and current use of primary health care. Ann Rheum Dis. 2001;60:91-7.

5. Cross M, Smith E, Hoy D, Nolte S, Ackerman I, Fransen M, et al. The global burden of hip and knee osteoarthritis: estimates from the global burden of disease 2010 study. Ann Rheum Dis. 2014;73:1323-30.

6. Weinstein AM, Rome BN, Reichmann WM, Collins JE, Burbine SA, Thornhill TS, et al. Estimating the burden of total knee replacement in the United States. J Bone Joint Surg Am. 2013;95:385-92.

7. Tang X, Wang S, Zhan S, Niu J, Tao K, Zhang Y, et al. The prevalence of symptomatic knee osteoarthritis in China: results from the China health and retirement longitudinal study. Arthritis Rheumatol. 2016;68:648-53.

8. Szoeke CE, Cicuttini FM, Guthrie JR, Clark MS, Dennerstein L. Factors affecting the prevalence of osteoarthritis in healthy middle-aged women: data from the longitudinal Melbourne Women's midlife health project. Bone. 2006:39:1149-55.

9. Wise BL, Niu J, Zhang Y, Felson DT, Bradley LA, Segal N, et al. The association of parity with osteoarthritis and knee replacement in the multicenter osteoarthritis study. Osteoarthr Cartil. 2013;21:1849-54.

10. Ham KD, Carlson CS. Effects of estrogen replacement therapy on bone turnover in subchondral bone and epiphyseal metaphyseal cancellous bone of ovariectomized cynomolgus monkeys. J Bone Miner Res. 2004;19:823-9.

11. Olson EJ, Lindgren BR, Carlson CS. Effects of long-term estrogen replacement therapy on bone turnover in periarticular tibial osteophytes in surgically postmenopausal cynomolgus monkeys. Bone. 2008;42:907-13.

12. Yang L, Li L, Millwood IY, Lewington S, Guo Y, Sherliker P, et al. Adiposity in relation to age at menarche and other reproductive factors among 300000 Chinese women: findings from China Kadoorie biobank study. Int J Epidemiol. 2017;46:502-12.

13. Stolzenberg-Solomon RZ, Falk RT, Stanczyk F, Hoover RN, Appel LJ, Ard JD, et al. Sex hormone changes during weight loss and maintenance in overweight and obese postmenopausal African-American and non-AfricanAmerican women. Breast Cancer Res. 2012;14:R141.

14. Lavet C, Martin A, Linossier MT, Vanden Bossche A, Laroche N, Thomas M, et al. Fat and sucrose intake induces obesity-related bone metabolism disturbances: kinetic and reversibility studies in growing and adult rats. J Bone Miner Res. 2016;31:98-115.

15. Wang F, Zhu J, Yao P, Li X, He M, Liu Y, et al. Cohort profile: the DongfengTongji cohort study of retired workers. Int J Epidemiol. 2013;42:731-40.

16. Kellgren JH, Lawrence JS. Radiological assessment of osteo-arthrosis. Ann Rheum Dis. 1957;16:494-502.

17. WHO Expert Consultation. Appropriate body-mass index for Asian populations and its implications for policy and intervention strategies. Lancet. 2004:363:157-63.

18. Reijman M, Pols HA, Bergink AP, Hazes JM, Belo JN, Lievense AM, et al. Body mass index associated with onset and progression of osteoarthritis of the knee but not of the hip: the Rotterdam study. Ann Rheum Dis. 2007;66:158-62.

19. Haukka E, Ojajarvi A, Takala EP, Viikari-Juntura E, Leino-Arjas P. Physical workload, leisure-time physical activity, obesity and smoking as predictors of multisite musculoskeletal pain. A 2-year prospective study of kitchen workers. Occup Environ Med. 2012;69:485-92.

20. Peplonska B, Bukowska A, Lie JA, Gromadzinska J, Zienolddiny S. Night shift work and other determinants of estradiol, testosterone, and dehydroepiandrosterone sulfate among middle-aged nurses and midwives. Scand J Work Environ Health. 2016:42:435-46.
21. Andersson T, Alfredsson $L$, Kallberg $H$, Zdravkovic S, Ahlbom A. Calculating measures of biological interaction. Eur J Epidemiol. 2005;20:575-9.

22. Gao W, Zeng C, Cai D, Liu B, Li Y, Wen X, et al. Serum concentrations of selected endogenous estrogen and estrogen metabolites in pre- and postmenopausal Chinese women with osteoarthritis. J Endocrinol Investig. 2010; 33:644-9.

23. Parazzini F. Menopausal status, hormone replacement therapy use and risk of self-reported physician-diagnosed osteoarthritis in women attending menopause clinics in Italy. Maturitas. 2003;46:207-12.

24. Zhang Y, McAlindon TE, Hannan MT, Chaisson CE, Klein R, Wilson PW, et al. Estrogen replacement therapy and worsening of radiographic knee osteoarthritis: the Framingham study. Arthritis Rheum. 1998:41:1867-73.

25. Nevitt MC, Felson DT, Williams EN, Grady D. The effect of estrogen plus progestin on knee symptoms and related disability in postmenopausal women: the heart and estrogen/progestin replacement study, a randomized, double-blind, placebo-controlled trial. Arthritis Rheum. 2001;44 811-8.

26. Sandmark H, Hogstedt C, Lewold S, Vingard E. Osteoarthrosis of the knee in men and women in association with overweight, smoking, and hormone therapy. Ann Rheum Dis. 1999;58:151-5.

27. Wluka AE, Davis SR, Bailey M, Stuckey SL, Cicuttini FM. Users of oestrogen replacement therapy have more knee cartilage than non-users. Ann Rheum Dis. 2001;60:332-6.

28. Sniekers $Y$, Weinans $H$, van Osch $G$, van Leeuwen J. Oestrogen is important for maintenance of cartilage and subchondral bone in a murine model of knee osteoarthritis. Arthritis Res Ther. 2010;12:R182.

29. Kim HJ, Oh YK, Lee JS, Lee DY, Choi D, Yoon BK. Effect of transdermal estrogen therapy on bone mineral density in postmenopausal korean women. J Menopausal Med. 2014;20:111-7.

30. Cortes-Prieto J, Vicente-Hernanz ML, Cortes-Garcia A, Keller J, del Rio RC, Brita-Paja Segoviano JL. Hormone replacement therapy: evolution of body mass index, bone mineral density, and lipid profile. Horm Mol Biol Clin Investig. 2013;13:19-40.

31. Wright NC, Riggs GK, Lisse JR, Chen Z. Self-reported osteoarthritis, ethnicity, body mass index, and other associated risk factors in postmenopausal women-results from the Women's Health Initiative. J Am Geriatr Soc. 2008; 56:1736-43.

32. Posthuma WF, Westendorp RG, Vandenbroucke JP. Cardioprotective effect of hormone replacement therapy in postmenopausal women: is the evidence biased? BMJ. 1994;308:1268-9.

33. Jorgensen KT, Pedersen BV, Nielsen NM, Hansen AV, Jacobsen S, Frisch M. Socio-demographic factors, reproductive history and risk of osteoarthritis in a cohort of 4.6 million Danish women and men. Osteoarthr Cartil. 2011;19: 1176-82.

34. Liu B, Balkwill A, Cooper C, Roddam A, Brown A, Beral V. Reproductive history, hormonal factors and the incidence of hip and knee replacement for osteoarthritis in middle-aged women. Ann Rheum Dis. 2009;68:1165-70.

35. Walter JR, Perng W, Kleinman KP, Rifas-Shiman SL, Rich-Edwards JW, Oken E. Associations of trimester-specific gestational weight gain with maternal adiposity and systolic blood pressure at 3 and 7 years postpartum. Am J Obstet Gynecol. 2015;212:499 e1-12.

36. Puhkala J, Luoto R, Ahotupa M, Raitanen J, Vasankari T. Postpartum weight retention is associated with elevated ratio of oxidized LDL lipids to HDLcholesterol. Lipids. 2013;48:1227-35.

37. Gkretsi V, Simopoulou T, Tsezou A. Lipid metabolism and osteoarthritis: lessons from atherosclerosis. Prog Lipid Res. 2011;50:133-40.

38. Liu Y, Zhang H, Liang N, Fan W, Li J, Huang Z, et al. Prevalence and associated factors of knee osteoarthritis in a rural Chinese adult population: an epidemiological survey. BMC Public Health. 2016;16:94.

39. Huerta C, Johansson S, Wallander MA, Garcia Rodriguez LA. Risk factors and short-term mortality of venous thromboembolism diagnosed in the primary care setting in the United Kingdom. Arch Intern Med. 2007;167:935-43.

40. Gomes MP, Deitcher SR. Risk of venous thromboembolic disease associated with hormonal contraceptives and hormone replacement therapy: a clinical review. Arch Intern Med. 2004;164:1965-76.

41. van Vlijmen EF, Wiewel-Verschueren S, Monster TB, Meijer K. Combined oral contraceptives, thrombophilia and the risk of venous thromboembolism: a systematic review and meta-analysis. J Thromb Haemost. 2016;14:1393-403.

42. Saure A, Heikkinen JE, Ylostalo P. The effect of two low-dose oral contraceptives and non-hormonal contraception on serum lipids and highdensity lipoprotein cholesterol. Contracept Deliv Syst. 1984;5:83-90. 
43. Grandi G, Piacenti I, Volpe A, Cagnacci A. Modification of body composition and metabolism during oral contraceptives containing non-androgenic progestins in association with estradiol or ethinyl estradiol. Gynecol Endocrinol. 2014:30:676-80.

44. Khoo C, Campos H, Judge H, Sacks FM. Effects of estrogenic oral contraceptives on the lipoprotein B particle system defined by apolipoproteins E and C-III content. J Lipid Res. 1999;40:202-12.

45. Diascro DD Jr, Vogel RL, Johnson TE, Witherup KM, Pitzenberger SM, Rutledge SJ, et al. High fatty acid content in rabbit serum is responsible for the differentiation of osteoblasts into adipocyte-like cells. J Bone Miner Res. 1998:13:96-106.

46. Sturmer T, Sun Y, Sauerland S, Zeissig I, Gunther KP, Puhl W, et al. Serum cholesterol and osteoarthritis. The baseline examination of the Ulm osteoarthritis study. J Rheumatol. 1998;25:1827-32.

Ready to submit your research? Choose BMC and benefit from:

- fast, convenient online submission

- thorough peer review by experienced researchers in your field

- rapid publication on acceptance

- support for research data, including large and complex data types

- gold Open Access which fosters wider collaboration and increased citations

- maximum visibility for your research: over $100 \mathrm{M}$ website views per year

At $\mathrm{BMC}$, research is always in progress.

Learn more biomedcentral.com/submissions 